\title{
„Hochkleben“ der Bauchfellschürze bei extremer Adipositas
}

Bei adipösen Patienten ist die Punktion der Blase oft nicht einfach, vor allem, wenn keine Hilfsperson anwesend ist. Wie der Eingriff trotzdem sicher gelingt, lesen Sie in folgendem Tipp.

Bei Eingriffen im Unterbauch wie z. B. bei der Einlage eines Blasenfistelkatheters in Rückenlage stört bei extremer Adipositas häufig die schürzenartig vorfallende Bauchdecke. Es ist nicht nur die Orientierung erschwert, auch eine Fehlpunktion der Blase mit u.U. deletärem Ausgang durch den noch größeren Abstand zum Hautniveau wird wahrscheinlicher.

Hilfreich ist es in derartigen Fällen, wenn eine Hilfsperson die Bauchfellschürze nach oben zieht. Ist diese nicht greifbar, hilft das „Hochkleben“ der Schürze durch 1-2 Streifen eines handelsüblichen KlebeVerbands ( $\mathbf{A b b} \mathbf{1}$ ): Die Anatomie ist wiederhergestellt und eine Punktion bei gestraffter und flacherer Bauchdecke nun sicher möglich.

\section{PD Dr. Andreas Wiedemann, Witten}

\section{Korrespondenz:}

PD Dr. Andreas Wiedemann

Urologische Klinik

Evangelisches Krankenhaus

im Diakoniewerk Ruhr gGmbH

Lehrstuhl für Geriatrie

der Universität Witten/Herdecke

Pferdebachstr. 27

58455 Witten

Tel.: +49/2302/175-2521

awiedemann@diakonie-ruhr.de

Interessenkonflikte: PD Dr. Wiedemann: Beratungstätigkeit: Dr. Pfleger, Pfizer; Vortragstätigkeit: Allergan, AMS Deutschland, Astellas, Berlin-Chemie, Jansen, Lilly Deutschland, Dr. Pfleger, Pfizer, PohlBoskamp; Studienfinanzierung: AMS Deutschland

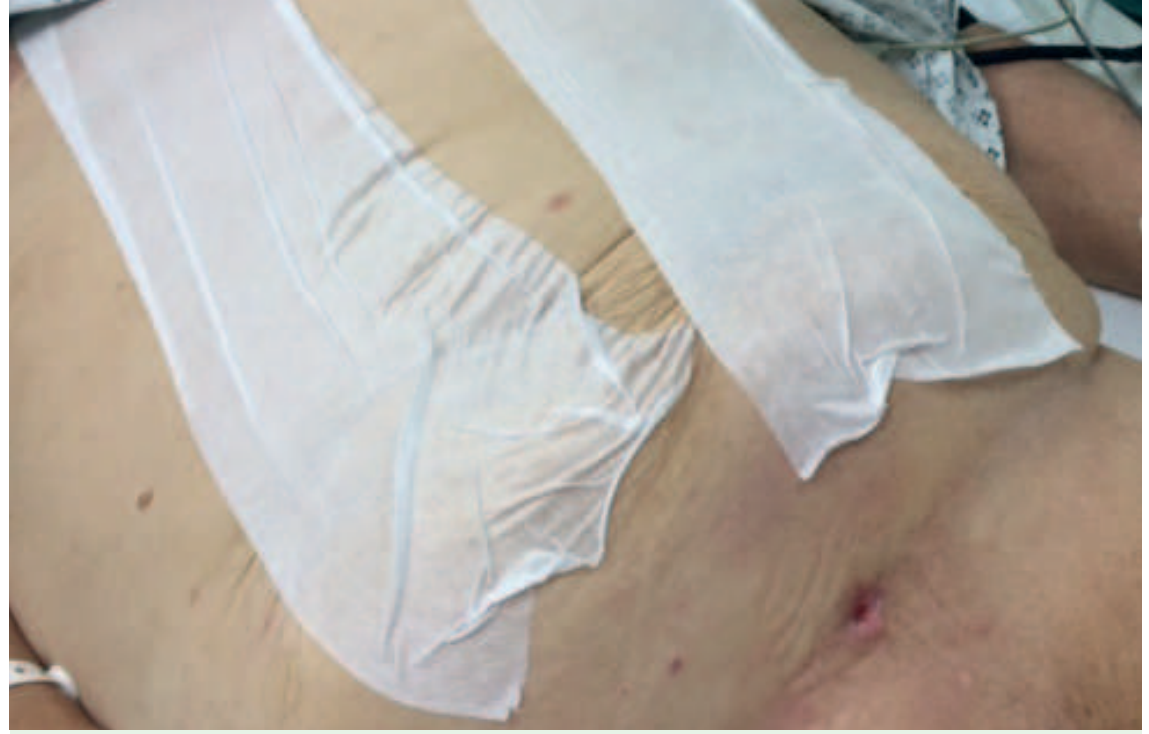

Abb. 1 Die ohne Reposition vor der Punktionsstelle eines Blasenfistelkatheters liegende Bauchfellschürze wurde mit selbstklebendem Verbandsmaterial "hochgeklebt“ - die Anatomie ist wiederhergestellt und (nach Auffüllen der Blase) eine sichere Punktion der Harnblase durch die nunmehr flachere Bauchdecke möglich. 